\title{
MERHUM HOCAM VE BAKANIM BEDRI GÜRSOY
}

\author{
Safa ÇETIN*
}

1959-1961 bgretim dönemlerine rastlyan 2 ile 3. sinıf tktisat ve Maliye Subesinde derslerini dinlemek mazhariyetine kavuştugum muhterem GÜRSOY'u kısa bir yazı çerçevesinde tahdit ve tavsif kabil olmamakla beraber, S.B.F. Maliye Bölümü Başkanı hocam Prof. Dr. Ismail TÜRK'ün hazırlamağı düşündükleri Armaģan için Maliye ve Gümrük Bakanlığına başvurarak mensuplarının katılmasını istemiş olması muvacehesinde, izleri henüz silinmemiş haurâu yansıtmak, edası muktazi bir vefa borcu haline geldiğinden; rahmetlinin eğitim ve bilim adamlığıla ikinci Dekanlık ve Bakanlığına iliş̧in bazı gozlemlerimiz aşağıda ozetlenecektir.

\section{ÖGRETICILIK VE ENSTITÜ YÖNETICLLIGI}

Hocanın itinalı giyimiyle muntazam ayrılmış saçlannnı süslediģi güler yüzünün etrafa yaydığı huzur içinde, merhum pederiyle Edip Âli BÂKI gibi şark ve garbin irfanına sahip hocalann bulunduğu Afyon Lisesi ve Mülkiyeden aldığı feyzin parılulanı yansıtan vecize ve beyitlerine ilaveten Maliye Bakanlığındaki memuriyetinden müntakil ilginç tecrübeleriyle zenginleştirdiģi derslerindeki musiki ahengi hâlâ kulaklanmızda yankılanmaktadır. Kamusal Maliye kitabının 1. cildine yazdığı Sungudaki "Hakka ve Halka hizmet" düsturuyla vatanperverliğini, bu kavramların taruşılmağa başlandığ bir donemde bile, hiçbir tereddüde mahal bırakmayacak sarahatta izhardan cekinmeyecek kadar medeni cesaret sahibi olan Hocamızın ders taksirleri zevkle izlenir ve sınavlarda güvenle yararlanılabilecek açıklıkla kayda alınabilirdi. Esasen imtihanı, talebeyi gafil avlayarak kendini isbat vesilesi haline getirmeyecek kadar olgun olan Hocamız her türlü insanî ihtiras ve zaaflardan tamamen berî idi. Yabanci deyim ve kaynakları eliyle tahtaya yazarken isulahat ve tabiraun tahlil ve tenkidini yapmaktan da geri kalmazdr.

Hocamız, merhum Ali ÇANKAYA'nın hazırladığı Yeni Mülkiye Tarihi ve Mülkiyeliler külliyatının 1859-1968 dơnemine ilişkin 1. cildinin 191. sahifesinde belirtilmesi unutulmakla beraber, bizzat izledigim Maliye Bakanlığndan aynimı§ Kemal KURDAŞ, Merkez Bankası Başkanı Münir MOSTAR ile Maliye Bakanlığı Tetkik Kurulundan Ragıp Hanyal gibi zevatın ihtisas mevzularını sunduklannı Maliye Enstitüsü

*Maliye ve Gümrük Bakanlıł̆ı, Maliye Başmưfettişi 
Konferanslannı düzenleyip bizzat yönettiłi gibi, S.B.O. nun Fakülteye çevrilmesindeki çabalarında da yararlandı̆̆ı idarî ve siyasî muhitiyle temasını daima koruyarak ilminin tatbikattan uzaklaşıp kendini tek: arlar duruma diş̧mesini dirayetle onlemiştir. Buna mukabil, ders ve ilmî mïzakerelc de de, hiçbir va.kit lahakküm yahut riyaya tevessül etmeyerek her seviyede fi cirlerin rảiatlıkla izharına firsat tanımıştır. Türkiye'ye çağnlmış olan Fransız Iktisat Profısörü A. Marchal'i haziruna takdimden sonra metnin çevirene onceden verilmiş olmasına rał̧mın, dinleyici sıralarıı geçerek sonuna kadar hatibi dinledigini hatırlıyorum.

\section{IKINCI DEKANI.IĞI}

Hocamın Dekanlığından unululamayan ilk arı, Fakülte binasından camlı kapıyla ayrılmış olan yatakhanele re gelip sııbahları elindeki çubul:la karyola demirlerine vurmak suretiyle talebeyi uyancirarak k: feterya ve korijorlarda vakit bldürenleri derslere kovalamasındaki tatlı sert inzibatıdı. Bu takibe karşı talebenin tepkisi ise, sadece "Bedros geliyor" çagnsıyla alelaccle giyinmek veya yatakhaıne ve koridorların bir tarafından obür yanına kaçmaktan ibaret kalıp, Hıcanın tekrar gelebiles:eł̧i endişesiyle zaten yeniden uyuyabilene de pek rasuanmazilı. Sınf kapılanndaki göz camlanndan ogreticilerin derse devamlarını denetlediğini (le görmüşiizdür.

Diğer bir hâdise de, o yıllard‘ asî gençliğe he:eslenip deri ceket giyen uzun boylu ve sakallı bir oğrencinin arka bahçıye getirdiği çol: güçlï bir motosikleti durduğu yerde çalıştırmała devamı üzer ne Dekătuk makamının pencerısinden "Hey sakallı" hitabıyla

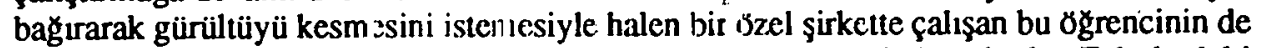
fazla itiraz etmeden ikara uyara: oradan uzaklas;masıdır ki, bu olaylar Fakültedeki münasebatın bir baba-jocuk: šmimiyeti içindeki ceryanına güzel birer ornek oluşturmaktadır.

Türkiye'nin ilk haritacılarınd:n olan Siyasî ve lktisadî Coğrafya hocamız merhum Prof. Dr. Hamit Sadi SELEN'in 1/t7'ler meyanında emekliye sevki üzerine Fakültenin 'divanhanesinde talebenir. iştirakiy/le düzenlediği tïrende, resmî muameleden müstakil tavır ve hareket gücünü ortaya k. syarak kemal-i hürmetle SELEN'in elini opmekten kaçınmamıştır. Öte yand:ın Maliye Tefti̧̧ Kurulunda ilk kez üstâd hitâbına layık gơrülüp Devletin muhtelif yükssk makâ:matında vazife yaptıktan sonra Danıştayda vergi davalarına bakan Daire Başkanıyken S.B. Fakültesiłıde Mahallî ldareler Maliyesiyle Türk Vergi Kanunlan Tatbik:atını büyiik bir ehliyetle: okutarak mevzuatın sene içindeki tadilâtunda teksirindeki ciımle clegi :ikliklerini bizzal yazdıracak ve dersi dinlemeyenlerin sınıftan çıkmalannı istı:yecek kiılar vazifesine baglı olan merhum Ismail Hakkı ÜLKÜMEN'e Profesörler Odasının kapısında "hocam" hitabıyla yol verdiygine şahit olmuşumdur.

\section{BAKANLIK DÖFNEM!}

Doç. Dr. Deniz BAYKAL'dan sonra Ord. Prof. Dr. Sadi IRMAK'ın kurdugu hükümetue Maliye Bakaniığına gelın Hocam ile Teftiş Kurulu Başkan Yardımcısı olarak teşrik-i mesai bahtiyarlığına eriş̧iłgim için çok. mutluyum. Bakanla ilk temasım gıyabımda hazırlanmış olan Kış Teftiş lzlentisinde denetlenmesi ơngörülmüş T.M.O. ne Maliye Müfettişinin gitrnesi üzerine bu kuruluşun o zaman bał̆lı bulunduğu Ticaret Bakanı Prof. Dr. Halûk ClLLOV imzasıyla Bakanlığımıza yollanmış, kendisine bağı olan teşekkülün denetiminin de Tic aret Teftiş Kurul.unun görev ve yetkisine girdiginden, 
malî denetimin durdurulması itirazını havi tezkere vesilesiyle oldu. Gơrüşsmek isteminin Özel Kalem Müdürlügünden telefonla bildirilmesi üzerine 0 anda benden başka yönetici olmaması dolayısıyla Kurulu temsilen huzuruna çıkıłıım merhum GÜRSOY titreyen elindeki yazıyı bana uzatarak mes'elenin izahını isteyince hemen orada Maliye Teskilat Kanununun Ticaret Bakanlığınınkinden muahhar tarihli olması sebebiyle Maliye Müfettişlerinin esasen bütün Devlete şâmil teftiş selăhiyetlerinde herhangi bir tereddüte mahal bulunmadığını ve mümanaata devam halinde Ceza Kanununa gơre suç işlenmiş olacağını arz ettim. O tarihteki Müsteşar rahmetli Cahit EREN'in de bil'ahare aynı yöndeki izahlan üzerine o yönde bir cevap hazurlanmasına kani olduysa da, muhatablarnn biraz daha ayak sürümesi dolayısıyla Hazine Genel Müdürü Dr. C. Tayyar SADIKLAR'nn denetime tabi olmaması halinde Ofise hiç bir nakit desteği yapılmıyacał̆ını bildirmesiyle tüm kayıtlar sonuna kadar açılmışt. Bu hadise de Maliyeyle Hazine arasındaki sıła rabıtanın onemini ortaya koyması bakımından iki teşkilâtu ayn Bakanlıklara bağlıyanlara oğretici bir ömek teşkil etse gerektir.

Ikinci muhaverem, Izmir'den sonradan bakan da olan bir oda mümessilinin şikâyetini ileterek gereł̧inin yapumasını istemesi dolayısıyla gerçekleşmiştir. Bu konuyu araşurarak bilgi vermek üzere tekrar Makama gidildił̧inde, Hazine Genel Müdür Başyardımcısı Sabahattin SARAÇLAR'ın yurdumuzda ilk defa başka Bakandan alınmış bir HAZMITT onayı üzerine hayali ihracat denetimiyle görevlendirilmem sonucu düzenlediğim iki geniş layıhada ileri sürdügüm teklifleri Hocaya arzla benimsetmege çalışmasına karşılık Merhumun, bazı itirazlarıyla gerekçelerin sağlamlıgıını sınarken buldum. Zira 12.10.1973 günlü layihamda prefinansman dơvizi adiyla yurda getirilip karşılığında hị̧ ihracat yapılmamı̧ havaleler için mevzuatta herhangi bir tanzime gidilmemiş olması dolayısıyla ihracaun üç ay içinde gerçekleştirilmesi veya yurda girdiği tarihteki rayiç üzerinden döviz olarak mevridine iade mecburiyetinin vaz'1; dơviz alım bordrolarıyla Türk parasına çevrilmiş prefinansman mukabilinde ancak tavassut eden bankadan ihracata izin verilerek muamelât arasında irtibat tesis ve takibinin temini; ihracatta vergi iadesi almak üzere Merkez Bankasına verilmiş dőviz alım bordrolannın kısmî ihracatta aslı yerine suretinin mutavassıt ticarî bankaya gönderilerek müteakip ihraç kısımlarının Merkez Bankasında kalacak asıl üzerinden takip ve tahkikinin sağlanması; 6.12 .1973 tarihli takririmde de, sırf kısa vadede döviz temini için bir yandan paramızın dış değerinin gençeğin alunda belirlenmişken ote yandan vergi iade oranlannın sunî̀ olarak yüksek tesbitiyle milli gelir ve servetten yurt içiyle dışındaki bazı zümrelere haksız ve karşılıksız kaynak aktanımına yol açıldığı rakamlarla kanıtlanarak aslında gerçeğin alunda transfer fiyatlanyla fatura düzenlenmek suretiyle yurt dışına daha once kaçırılmış vergi dışı hasılatın yurda getirilmesine fırsat veren mevzuat boşluğunun Hazineyi uzun vadede katmerli zarara sokan bir imtiyaz oluşturması sebebiyle vazgeçilmesi onerilmekte idi.

Teklife dayanak olarak da, Ceza Usul Hukukunun pîri olan Prof. Dr. Nurullah KUNTER'in "Suçun Kanunî Unsurları Nazariyesi" kitabının 163. sahifesindeki 111 no. lu bendden aktardığı "Kanunda derpiş edilmemiş hukuka uygunluk sebeblerinin kıyas yoluyla elde edilebileceğini ve bu kıyas içinde bu sebeblerde hâkim olan içtimaî ehemmiyeti fazla olan menfaatin ehemmiyeti az olan menfaata tercihi prensibinin esas tutulacağını, ehemmiyeti takdirde kemmî değil, keyfí bir olçü kullanılacağını sðyliyen BETTIOL (Diritto Penale, sh.232) un fikirlerine iştirak etmekteyiz" ilmî içtihadını ileri sürmüstüm. Böylece yurdumuzun, 1950 den sonra gözükara daldığı iktisadî serbestûnin doğurduğu dengesizlik ve başıboşluktan kurtanlarak vergiden başlaması gereken içtimaî adalet ve hukukî mazbutiyet kavramlanna Devleti biraz olsun dőndürmeği amaçlıyordum. 
Bu ơnerilerin bir ôlçüde benimsenmesi üzerine matbuatıa başıyan, kırtasiyeciliģin geri geldigine ilişkin itirazların mevzua tì tekrar açurdı̣̆s lavizkâr rahneler, iki kere daha aynı hatalara düşülerek Hazinının dolaylı yoldan zarara u'şrat lilmasına sebebiyet vermiştir.

Hocanın Maliyenin başına gıttirildiģi tarihlerte, Merkez Bina Toplantu Salonunda Bakanlık erkânının da katuldığı $\mathrm{T}$ tftis Kurulu konieranslarından biri zamanın Bütçe ve Malî Kontrol Genel Mǜtürul merh ım Nihat TEZEIs a arafindan, dairesinin gőrev alanına ilişkin konularda verilrnişti. Genel Müdür, tukctiminin sonuna doğru gayn nizamî kullanıldığını gördügü resmî arak aların plâkalarnndan dairelerini tesbitle ikaz yoluna gittigini belirtince, ben de tenl:id sadedinde, halen uygulanan masraf mevzuatı deģiştirilmeden ve maliyet esasına müstenit bir etkenlik muhasebesi benimsenmeden boyle arızi yőntemlerle müessir bir denetim sał̣] anamıyacağını sőylemiş idim. 1975 bütçe kanununa bu eleştirimin de 6 ukisiyle "Bütşe politikası ve malî kontrol" başlığıyla

"A) Maliye Bakanı Genel bütçeye dahil dairelerle katma bütçeli idarelerde, harcamalarda tasarrufu sağlamak, tutarl, dengeli ve etkili bir bütçe politikası yürütmek amacı ile giderlere iliłkin kanın, yönetmelik ve kararnamelerin uygulanmalannı düzenlemek uzere gerekli tedbirl:ri almaya, starıdardarn tesbite ve takyitler koymaya yetkilidir.

"B) Maliye Bakanı kuruluşlı nn hizmet programlanının etkin tasarruflu bir şekilde gerçekleştirilmesini sag lamak am acı ile, genel bülçeye dahil daireler ile katma bütçeli idarelerin ellerinde bul..nan motcrilu nakil vasıtalirn ile is makinelerine ilişkin gerekli standartları tesbite ve takyitler koymaya yetkilidit. Kuruluşlar, bu konu ile ilgili olarak Maliye Bakanlığınca isttnilen bilgileri vermekle yükkümliidür.

"C) Giderlerinin yaurısından faxlası Hazine yardımılan ile karşılanan ve fakat katma bütçeli idare durumunda bulunmayan, ozzel kanuıllarla kurulmuş kamu kuruluşlannın hizmet programlarını j'll içinde diizenlemeye ve burnlar için harcamalar ve istihdam esasları yönünden ger:kli stand.utları tesbite vi: takyitler koymaya Maliye Bakanı yetkilidir.

"Bu madde hükmi:, ozel ida eler, belediyelè, dðner sermayeli kuruluşlarla Kamu Iktisadí Teşebbüsleri hakkında dıı uygulanır." maddesi dercedilerek mealen günümüze kadar korunmuştur.

Bakanlığının hitamında Istar bul Iktisat Fakülttesi Maliye Enstitüsünce kendisinden icraatuna müteallik bir konferans istenmişti. Rahınetli bu maksatla Üniversite Merkez Binasındaki Doktora Salonuna girı:rken önden 3. stranıı kapı tarafında gördügü benim her zamanki tevazuuyla elimi słkar kk hauır sordukıan sonra kürsüye yönelmeği ihmal etmemişti.

Izahatı biraz uzayıp olą̧an süreyi aşınca, konuşmayı kesmesinin istenip istenmediğini sorduğu Enstitü Müdürü Prof. Dr. Bedi N. FEYZIOĞLU, bazı oğretim üyelerinin sıkınt emarcleri göstermelerine ragmen, "üstad" hitabıyla takdirin kendisine aid olduğunu beyanla baş̧ka bịr sabır ve nezaket ơrne gi sergilemişti.

Siyasî sebeblerle güüenoyu alamamasına rặ:men aylarca süren hükümet icraatının sunulması bitip mutad i.sule tevfi'can sorulara ges.ldiģinde, ben 29.1.1975 gün ve 15133 sayılı Resmi Gazetede münteşir t Inaya:a Mahkerıesinin 21.11.1974 tarih 1974/26 esas 
ve 1974/48 sayılı karanyla 1974 Bütçe Kanununun müteaddit ahkâmının Anayasaya aykınlık sebebiyle iptal edilmiş bulundư̆unu düşünerek anılan bu yeni hükmün de 1961 Anayasasının 5, 8 ve 126. maddelerine aykın olup olmadığıyla bu hükmün Devletteki israfı önleyip ónleyemiyeceği konulanındaki fikrini sormuştum. Hoca, herhalde zamanın da epey ilerlemiş olması sebebiyle bu ilâvenin çok onem taşımadığı mealinde bir cevab vermişti. Halbuki Anayasa Mahkemesinin malî hukuk zaviyesinden nirengi sayılabilecek olan mezkûr Karanndaki "Bu durum, esas metinlerinde mevcut olmayan bir hükmün, Bütçe Kanunu ile eklemek yoluyla sözü geçen kanunlarda değişiklik yapılmı̨ oldư̆unu açıkça ortaya koymaktadır.

"Her ne kadar kanunlann esas hükümlerinin olduğu gibi kalmakta olmasına ve sơzü geçen değişikliklerin bir malî yıl için geçerli olup yılın bitmesiyle, asıl kanun hükümlerinin kendiliklerinden yürürlüklerini sürdürmeye başlayacaklarına bakalarak bütçe kanununun, ơteki kanunlarda bir değişiklik meydana getimediği düş̧ünülebilirse de, bir malî yıl içinde kanunun asıl hükmünün uygulanmasını durdurduğu ve getirdig̛i değişiklik doğrultusunda uygulamayı zorunlu kıldığı da bir gerçektir. Şu halde bütçe kanunun, asıl kanunu belli bir süre için deģiştirmiş oldugu kuşkusuzdur. Bủ değişikliģin bir malî yıl için geçerli olması da sorunu deģiştiremez, çünkü değişiklik bir günlüik süre için bile olsa, aynı niteliği ve etkiyi gősterir.

"Öte yandan, sőz konusu miktarlara ilişkin hükümler, gőrüldügü gibi birer kanun ile düzenlenmişlerdir. Bunların, koşulların ve gereksinmelerin yeni gereklerine uydurulması da yine bir kanun ile yapılabilir. Bir başka deyimle bu konulardaki düzenleme, yasama organının genel nitelikteki yasa yapma yetkisi alanına girer. Oysa bütçe yapma işi özel nitelił̧̣i olan bir yasama işidir ve bu ózelliģi nedeniyle de bütçe kanunlarına bütçe ile ilgili hükümler dışında hiçbir hüküm konulamaz.

"Gơrüldüğü gibi Anayasa (kanun koymak, deģiștirmek ve kaldırmak) işi ile (bütçe kanun tasarılannı görüşüp kabul etmek) işini ayn nitelikte yetki alanlan saydıł̆ından deģişik biçimde belirlemek yolunu seçmiştir.

"Boylece bütçe kanunlannı ơteki kanunlardan ayn tutan Anayasa ilkesi karşısında; bir kanun hükmünün ancak aynı nitelikte olarak hazırlanıp kabul edilen bir başka kanun hükmü ile değiş̧tirilebilmesinin veya kaldırlabilmesinin mümkün olabileceğini, bunun gibi büıçe kanunlan hükümlerinin de aynı nitelikte hazırlanmış ve kabul edilmiş bulunan bütçe kanunu ekleriyle deģiştirilebileceğini kabul etmenin zorunlu olduğu, doğal olarak ortaya çıkmaktadır.

"Bu açıklamadan, bir kanun hükmünün genel anlamdaki bir kanun hükmü ile deģiştirilmesine veya kaldırılmasına Anayasa ilkelerinin olanak tanıdığı kolayca anlaşılmaktadır.

$+$

"Buraya kadar yapılan açıklamalardan doğal olarak çıkartılacak sonuç Anayasanın birbirinden tümüyle ayn olarak düzenlediği bu değişik yasama yöntem ve biçimlerinden belli birisine göre oluşturulmuş bir yasama belgesinin değiştirilmesinin veya kaldırılmasının da ancak aynı yöntem ve yollardan geçilerek sağlanabileceğinden ibarettir. Esasen hukukun genel kurallan da, hukuk alanında geçerli olan herhangi bir belgenin deģiştirilmesinin veya kaldırılmasının da, tersine bir hüküm olmadıkça veya 
yetkili bir máhkeme karan bulurmadıkça, o beļ̣,enin hazırlanmasında ve geçerli hale gelmesinde uygulanmış bulunaı yol ve yőnten:lerden geçirilmek yoluyla mümkün olabileceği dogrnultusundadır.

"Bu duruma göre bir kanun hükmünün mali yıl gibi geçici bir süre için bile olsa, bütçe kanunu ile değiştirilmesin: veya kaldınılrıasına olanak bulunmadığı gibi oteki kanunlarda da bütçe kanunu ile ilgili ödenek hükümierinin yer alması aynı nedenlerden ótürü olanaksız oldugundan her iki hale de uymayan bir hüküm, Anayasanın 92, 93 ve 94. maddelerine aykırı düşer.

$"$

"Anayasa tasarısında bu kural (madde :125), 'Bütçe Kanununa malî hükümler dışında hiçbir hüküm konulan:az' biçiminde iken Temsilciler Meclisindeki birinci gőrüşme sırasında bir üye 'malî hükümler deyimi üzerinde durarak, erek, bütçe uygulamasıyla ilgisiz kanunların Bütçe Xanur.unda yer almaınası olduğuna gơre deyimin, ereği karşılamadığını ileri sürmüş ve kıımisyondan açık lama istemiştir. Komisyon bu konuda bir açıklama yapmadan oteki görï̧şleri de gőzónijunde bulundurmak üzere maddeyi geri almış ve yeniden düzenlerken 'mâh hükümler' dey imini 'bütçe ile ilgili hükümler' olarak düzeltmiş ve madde bőylece Ternsilciler Meclisindı: kabul edilmiştir.

"Şu duruma göre Anayasanın 126. maddesinin son fikrasında yer alan 'Bütçe ile ilgili hükümler' deyimini, malî nitelikte sükïin anlamına değil, bütçenin uygulanmasıyla ilgili, uygulamayı kolaylaşuncı v:ya, kanun konusu olabilecek yeni bir kuralı kapsamamak kçşulı alıııda, açıklayıcı ritelikte hükümler olarak düşünmek zorunlulự̆u vardir.

\section{"Şurasinın da gozênünde bulındurulması yerinde olur.}

"Bu kanun kuralının bütçeden harcamayı gerektirir veya bütçeye gelir getirir nitelikte bulunması, onun 126. mııddede öngörüldıìgü gibi, 'Bütçe ile ilgili hükümler'den sayılmasına neden olamaz. Çünkii hemen her kśuunda harcamalara yol açabilecek bir veya birçok hükümler bulunabilir. Keza her vergi kanunu bütçeye belli bir kaynaktan gelir saģlar. Bütçe kanunlanyla itteki kanunlar aıasında mevcut olan bu (Gelir-Gider) ilişkisinin, sőz konusu kanunlarnn, 126. maddede yer alan 'bütçe ile ilgili hüküm' deyiminin kapsamı içinde sayılnıasına olanak vordiği kabul edilecek olursa bütün bu kanunların, sőz gelimi tarım, orman, eğitim, savunma, sağlık ve benzeri kamu hizmetlerini düzenliyen pek çok kanunun ve tǜ) vergi kanunlanının 'bütçe ile ilgili' sayılarak degiş̧irilmeleri veya kaldırılmaları $\mathrm{j}$ ̧̧in bütçe kanunlarına birer madde konulmasına gidilebilir. Oysa $t u$ kanunlar, büi.çenin yapısı ile, onun uygulanması yöntemleriyle ve bütçenin, Arayasanın 126. maddesinde belirtildigi gibi yıllık harcamaların saptanmasından ilaret olan temel ereģi ile ilişigi bulunmayan, yasa koyucunun, herhangi bir alanda belli bir erek doğ ultusunda ve bütçelerden tüm değişik yöntemlerle oluşturduğu düzenlemelere ilişkin yasama belgeleridir.

"Bütçe ile ilgili hüküm' deyimine dayanarak, bir kanunun gider veya gelirle ilgili kurallannın bütçe kanunlarıyla değiştirilebileceğgi yolunda bir görü̧ ve uygulama Anayasanin ......92 ve 93. maddelerini, gelirle ilgili veya gidere yol açabilecek kanunlar bakımından işlemez duruma sokar ve 94 . madılede yalnız bütçe düzenlemelerinin özellikleri dolayısıyla ayncalıklı olarak öngörülen pek sınırlı nitelikteki yola, Anayasa 
koyucunun ereğine aykın olarak genişlik ve genellik kazandurir. Oysa 126. madde sözü geçen kuralın tek ereğinin, bütçe kanunlanın, bünyeye yabancı hükümlerden ayıklamak ve derli toplu bir düzenleme ile bu kanunlarda gerçek anlamda bütçe kavramı dışında kalan konulara așla yer vermemek olduğunda kuşku yoktur." gerekçesiyle 1974 bütçe yasasının 1975 yılına ilişkin kanundaki yeni hükme benzer dokuz maddesini kısmen iptali mevzuunda Hocamın ilmî içtihadiyle siyasî ve idarî mütalâasını రđgreneceğimi düşünüyordum. Cevabının kısalıgı beni, o zaman maddenin, Bakanın bilgisine sunulmadan memurlarca bütçe tasansına eklendiği sonucuna gơtürmüş̧ua. Fakat bugün, mezkûr hükmün son seneye kadar Anayasa Mahkemesi iptaline takalmadan tekerrourine rağmen, muhasebece desteklenen birim maliyetlerinin yokluğundan rakamlı staridartlar geliştirilemeyip israfın da ónlenemediğini gördükten sonra, Hocanın icazıyla mes'elenin idrakini samiinin ferasetine bırakmış olduğunu anlamaktayım. Mayıs 1992 başlannda, Anayasa Mahkemesinin henüz Resmî Gazetede yayınlanmamış kararıyla mezkâr maddenin doner sermaye, fon, K.1.T., ozel idare ve belediyelere iliş̧in son bendinin iptal edilmiş oldugu Bütçe ve Malî Kontrol Genel Müdürü Erdogan ONER'den telefonla oğrenilmiştir. Diğer bendlerinin de aynı akıbete maruz bulunmaları sebebiyle Maliye Gümrük Bakanlığının kolayına gelen-bu tatbikata hukukilik kazandırabilmek için Anayasayla Muhasebe-i Umumiye Kanununa bu konuda daha sarih müeyyideler vaz'1 icabetmektedir. "Torsion" veya "clavier budgétaire" deyimleriyle eleştirilmesine rał̆men, Fransa'da da hâlâ vazgeçilemeyen bu yasal saptırımın ónlenmesi, taknin usulu bakımından mevzua daha fazla ciddiyet ve meşruiyet kazandıracakur. Aslında son Anayasanın 11. maddesiyle de çelişip meratip ve selahiyet kargaşasına yol açan kanun hükmünde kararnamelerle, seçimli yönetime geçildikten sonra fazlasıyla suistimal edilerek halktaki Devlet ve nizam saygısını büyük ollçüde zaafa ựratan adlí, malî ve sair idarî aflara karşın amme masraflarına inzibat ve tasarruf getirmek gibi çok muhik bir amaçtan kaynaklanmasına mukabil Maliye Bakanlığının Meclis yetkilerini istediği gibi kullanmasına müncer olan bu alışkanlığa, saymanlıklardan geçmeyen konularda sair bakanlıklan yeterince yönlendiremediği de nazara alınarak, son verilmesiyle daha sağlam kıstaslar geliştirilmesine imkân verecek mali denetimin güçlendirilmesi gerekmektedir. Ancak, Anayasaya tatbiki hüküm mahiyetinde yaptunm getirilemeyeceği yahut Maliyeye anî tedbir yetkisi temin zaruretine sığınılarak bu fikrin reddi halinde ise, 1982 Anayasasının 161. maddesindeki "Bütçe kanununa, bütçe ile ilgili hükümler dışında hiçbir hüküm konulamaz." fıkrasının tamamen ilgası, hukukî ve mantıkî bir mecburiyet haline gelmektedir.

\section{SAIR MEŞGALELERI}

Maliye Başmüfettişi Orhan GÜVEN ile birlikte birkaç sene Boğaziçi Üniversitesi murakıplığ da yapmış olan muhterem Hocamız ilmin kuruluk ve sınırlılığını şirin enginligiyle tamamlayan eserlerine inzimamen Bakan iken katıldığ ${ }_{1}$ tơren ve toplantularda bile çevresini büyük bir şevkle saran çömezlerinden esirgemediği vaaz-u nasihatlerle zihin ve gönüllerinde ebediyyen silinmeyecek müstesna yerini almış bulunmaktadır.

Aziz ruhuna Allahtan rahmet ve çok sevdiği vatanıyla halkımıza da başsağlığı diliyorum. 